\title{
Kernos
}

Revue internationale et pluridisciplinaire de religion grecque antique

$10 \mid 1997$

Varia

\section{L.-M. L'HOMME-WÉRY, La perspective éleusinienne dans la politique de Solon}

\section{André Motte}

\section{OpenEdition}

\section{Journals}

Édition électronique

URL : http://journals.openedition.org/kernos/689

DOI : 10.4000/kernos.689

ISSN : 2034-7871

\section{Éditeur}

Centre international d'étude de la religion grecque antique

\section{Édition imprimée}

Date de publication : 1 janvier 1997

Pagination : $357-358$

ISSN : 0776-3824

\section{Référence électronique}

André Motte, « L.-M. L'Hомme-wérr, La perspective éleusinienne dans la politique de Solon », Kernos [En ligne], 10 | 1997, mis en ligne le 12 avril 2011, consulté le 23 septembre 2020. URL : http:// journals.openedition.org/kernos/689; DOI : https://doi.org/10.4000/kernos.689 
aphone " (p. 109) paraît, si l'on ose dire, des plus savoureuses) et, à y regarder de près, les exemples utilisés comme pièces des différents « dossiers " n'apportent peut-être pas toujours toutes les précisions souhaitables. Prenons le cas de l'épisode des « chèvres d'Aigeira », auquel nous avons eu l'occasion de nous intéresser nous-même dans le cadre de recherches sur l'Achaïe et sur Pausanias (voir Y. LAFOND, Artémis en Achaïe, in $R E G, 104$ [1991], p. 410-433) : il est regrettable que, dans la présentation de la cité d'Aigeira (p. 222), aucune mention ne soit faite des travaux de l'École autrichienne (voir W. Alzinger [et al.], Klio, 67 [1985], p. 389-451; 68 [1986], p. 5-62 et 309-347), dont les fouilles, qui se poursuivent encore actuellement sous la direction d'A. BAMMER, ont une importance équivalente à celle des recherches menées par R. FELSCH à Hyampolis et ont permis de renouveler les conclusions de FRAZER ou ANDERSON (cités p. 222, n. 109). L'Artémis de Pellène citée plus loin (p. 223) d'après Pausanias semble bien avoir été une Artémis chasseresse, mais ne porte pas l'épiclèse d'Agrotéra, comme semble le sous-entendre l'A., dans le texte du Périégète. S'agissant enfin des types monétaires d'Artémis, ne serait-il pas intéressant de signaler qu'à Aigion aussi, en Achaïe, on retrouve des représentations d'une chasseresse dadophore? Dans le cas de l'Artémis Laphria de Patras, et à propos de l'introduction de son culte par Auguste dans la nouvelle colonie, la monographie de J. HERBILlon (citée p. 246-247) n'est plus la seule référence possible : voir F. TrotTa, Il sinecismo di Patrasso in Pausania e Strabone, in $P P$ (1993), p. 428-444. Mais ces quelques réserves voudraient montrer seulement que, dans l'optique choisie par l'A., ce qui compte surtout, c'est d'utiliser la documentation au service d'une argumentation qui puisse réussir à tenir ensemble les fils de l'histoire, de l'histoire des religions et de l'imaginaire. Et, de fait, à travers les détours et retours savamment calculés dans lesquels est entraîné le lecteur, on perçoit l'enthousiasme de l'A. à construire une démonstration qui s'inscrit dans le sillage des meilleures approches anthropologiques de la Grèce ancienne (voir les travaux fréquemment cités de J.P. VERnANT et de « l'École de Paris »). Il faut donc être prudent en utilisant le double index (textes cités et index général) qui clôt ce volume : les textes et les sujets auxquels ils renvoient doivent être toujours replacés dans le mouvement de la démonstration. Dans sa préface à un ouvrage édité par Chr. Bron et E. KASSAPOGlou (L'image en jeu, de l'Antiquité à Paul Klee, Univ. de Lausanne, éd. Cabédita, 1992, p. 12), $\mathrm{Cl}$. BÉRARD faisait remarquer que, pour apprécier la richesse des systèmes iconographiques, «il existe heureusement plusieurs serrures et plusieurs clés » et ajoutait : «théoriquement, les unes ne sont pas meilleures que les autres. Elles ouvrent simplement des compartiments différents ». Une telle remarque pourrait très bien convenir, nous semble-t-il, au présent ouvrage, replacé dans le contexte des études consacrées à la personnalité d'Artémis et, plus généralement, à la guerre dans le monde grec antique.

Yves LAFOND

(Université d'Artois)

Louise-Marie L'Homme-WÉRY, La perspective éleusinienne dans la politique de Solon, Genève, Droz, 1 vol. $16 \times 24,5 \mathrm{~cm}, 391 \mathrm{p}$. (Bibliothèque de la Faculté de Pbilosophie et Lettres de l'Université de Liège, fasc. 268). ISBN Broché : 2-87019-268-1; ISBN Relié : 2-87019-068-9.

Cet ouvrage est d'un grand intérêt pour la compréhension de l'œuvre politique de Solon et pour l'exégèse aussi de son œuvre poétique. Prolongeant une thèse originale 
défendue jadis par $\mathrm{H}$. VAN EFFENTERRE au sujet de la libération par l'homme politique athénien du territoire d'éleusis qu'avait conquis Mégare, il l'enrichit par une série d'études approfondies qui exploitent, avec beaucoup d'ingéniosité et d'esprit critique, non seulement les témoignages des historiens anciens, mais aussi quantité de données religieuses, politiques, économiques, militaires, topographiques même, patiemment rassemblées et bien mises en perspective. En dépit de cette multiplicité d'approches, le travail est remarquablement structuré, sa méthode pouvant être qualifiée de circulaire : chacun des six premiers chapitres contribue à étayer le propos central à partir d'éclairages différents.

Si la thèse d'une reconquête par Solon sort considérablement renforcée de ces analyses, il reste à expliquer pourquoi toute l'historiographie antique a passé sous silence l'événement. Le dernier chapitre relève, de façon remarquable, ce défi en montrant comment l'histoire athénienne qui prècède et qui suit l'illustre législateur a été profondément marquée par une souillure (agos) encourue de la part de la déesse éleusinienne à la suite du sacrilège cylonien, malédiction dont on évite soigneusement de rappeler le souvenir offensant parce qu'elle passe pour avoir été la cause de plusieurs sécessions de la cité des mystères et parce qu'on continue d'en redouter les néfastes effets.

On peut prévoir que toutes les interprétations et les reconstructions habiles que propose l'A. ne rencontreront pas l'adhésion unanime des historiens spécialistes, mais l'ouvrage, très documenté et solidement argumenté, fera date. La qualité de l'information en matière religieuse et le parti nouveau que l'A. réussit à tirer des faits pour éclairer la pensée et l'œuvre soloniennes méritent en particulier l'attention. Si la bibliographie est riche, on regrettera cependant l'absence d'index.

André MOTTE

(Université de Liège)

Annie Verbanck-Pí́rard, Didier Viviers (éds), Culture et Cité. L'avènement d'Atbènes à l'époque archä̈que. Actes du Colloque international organisé à l'Université libre de Bruxelles du 25 au 27 avril 1991 par l'Institut des Hautes Études de Belgique et la Fondation Archéologique de l'U.L.B., Bruxelles, 1995. 1 vol. $17 \times 24$ cm, 252 p., 26 ill. ISBN : 2-9600094-0-1. Diffusion de Boccard.

Comme le soulignent les éditeurs, l'objet du colloque dont le présent volume publie les actes était de définir la relation entre Culture et Cité " pour mieux percevoir les conditions de l'avènement d'Athènes à l'époque archaïque ». Définissant la « culture », ils y reconnaissent " le comportement général des groupes humains, acquis par l'éducation comme par l'expérience, la paideia en grec [...] Ainsi comprise, la culture peut être bien plus qu'un révélateur de l'évolution politique et sociale d'Athènes; elle a pu également jouer un rôle actif dans cette évolution, et notamment dans la conquête et la nature de sa citoyenneté ».

Loin d'isoler Athènes en revenant à un athénocentrisme dépassé, les participants à ce colloque l'ont étudiée en confrontant son modèle à celui d'autres cités - Corinthe, Argos, les cités ioniennes -, en l'appréhendant dans la durée, de l'époque géométrique à la tyrannie qu'ils perçoivent comme une variante de structure aristocratique. Dans l'optique de déterminer les rapports entre Culture et Cité, ils ont abordé toutes les facettes de la culture athénienne, : céramique (J. BOARDMAN); pratiques littéraires avec 